\title{
LA GRAMÁTICA EN BANDEJA DE PLATA
}

Marlene Rall

1. La gramática no es necesaria; sin embargo, puede llegar a ser útil A mediados del siglo pasado apareció en México un Método Práctico para Aprender el Idioma Alemán ${ }^{1}$ en cuyo prefacio el autor, Oloardo Hassey, adopta un tono sorpendentemente moderno:

Un método bien arreglado y un buen maestro pronto nos convencerán de que se puede aprenderlo (el alemán) y hablarlo correctamente sin haber jamás puesto el pie en Alemania. (...) La naturaleza nos enseña el mejor modo de enseñanza; niños de poca edad hablan su idioma sin saber reglas; enseñemos del mismo modo. Cuando se sepan las expresiones más precisas y se sepa combinarlas, entonces que vengan las reglas necesarias. (...) El principiante no tiene necesidad de la gramática. (Prefacio sin indicaciones de página.)

Posteriormente, sugiere al maestro que primero presente oralmente cada una de las lecciones y sólo después por escrito, y que no pase a la lección siguiente sino hasta que se hayan dominado a la perfección todas las palabras y oraciones. Causa sorpresa, entonces, descubrir que en la lección 1 de la primera parte, la Introducción, se practique el paradigma completo de los artículos definidos y de los indefinidos; en la lección 2, las formas am, contracción de an dem, como sucede en am Tisch (a la mesa); an's, de an das, an's Fenster (junto a la ventana); im, de in dem, im Leben (durante la vida); etcétera. En la lección 3 se presentan las diferentes declinaciones de los sustantivos; y a partir de la lección 19 se enlistan una a una las tablas completas de conjugación de los verbos en todas sus personas, tiempos y modos, e incorporando incluso formas rebuscadas y en desuso como: dap ich gehabt haben würde (p. 47), dap ihr werden werdet (p. 51), dap wir gelobt worden sei werden (p. 65). Para no hacer tan pesado el aprendizaje se incluyen entre las tablas de conjungación y las de declinación listas de vocabulario y ejercicios, como por ejemplo: Wo sind meine Schuh und Stiefel? (¿En dónde están mis zapatos y botas?), Was ist die Ursache vom Kriege? (¿Cuál es la causa de la guerra?), Dieser Soldat hat Muth (Este soldado tiene valor), Er geht zu Fu und ich reite (Êl va a pie y

1 Hassey, 1872, sin página. 
yo a caballo), Sind Sie schon müde? (¿Ya se cansó?) En todos los casos las frases van acompañadas de su respectiva traducción.

La segunda parte, que lleva el título explícito de Gramática, proporciona, por un lado, reglas tanto para la formación de palabras como para la declinación de los adjetivos, una tabla de verbos irregulares y listas de preposiciones, conjunciones e interjecciones; por otro lado, responde a preguntas como: 1) ¿Cuándo se usa la letra p? 7) ¿Cuándo se utiliza el artículo indefinido? 21) ¿Hay reglas fijas para la colocación del verbo en la frase? 23) ¿Qué casos rigen los verebos alemanes?²

La tercera parte, intitulada Diálogos, contiene oraciones ordenadas temáticamente que sirven para "facilitar la conversación", y en las cuales sólo se emplean "expresiones cotidianas de la buena sociedad" (p. 149). La cuarta parte consta de textos para leer: fábulas, historias edificantes, poesías y proverbios, como el siguiente formulado por Goethe:

Lehrbücher sollen anlockend sein: das werden sie nur, wenn sie die heiterste zugänglichste Seite des Wissen's und der Wissenchaft darbieten (p. 277).

Los libros de enseñanza deben ser atractivos: lo serán sólo si nos of recen el lado más grato y asequible del saber y de la ciencia.

Al final del libro se ofrece un Modelo de Análisis (pp. 291-302), en el cual se aprovecha cada una de las palabras empleadas en un texto para repasar las reglas que se les aplican. Este modelo pone de manifiesto que no había que tomar $\tan a 1$ pie de la letra el postulado programático, propuesto en el prefacio, en el sentido de dejar que el alumno aprenda la segunda lengua, como los niños la primera. $O$ ¿constituye el M P el método más avanzado que se pudo concebir en ese momento?

En esa época una clase de idioma no debe haber incluido otra cosa que no fuera gramática, por lo menos cuando quien la impartía era un docto. Como se desprende de lo dicho por Hofmannsthal, la clase de idioma debe haber sido tanto más aburrida cuanto más preparado quien la impartía:

A quienes enseñan cualquier lengua como si estuviera muerta se les denomina filólogos. A los otros, a los que enseñan lenguas vivas y lo hacen vívidamente, simplemente se les llama profesores de idiomas. Los profesores son despreciados por los filólogos no obstante que entre estos últimos se encuentren los hombres más despreciables de la tierra, mientras que entre los profesores se hallan muchos que son buenos y sensatos. Esto se debe al hecho de que casi todos ellos fueron antes algo diferente, simples hombres que sólo por casualidad han llegado a ser profesores de idiomas. (...) Todos ellos han pensado en su propio idioma, han tenido deseos, han soñado, han dado y recibido respuestas, han experimentado el contenido infinito de palabras vanas, han sentido la desgarradora y extasiante fuerza del discurso, mucho antes de que el destino los llevara a preguntar: ¿En dónde dejaste el cortaplumas de tu abuela? Y acto seguido a responder: El buen almirante está en el jardín y llora sin consuelo. ${ }^{3}$

2 Véase en el Apéndice uno de los primeros ejemplos de un tipo de gramática de dependencia.

3 Hofmannsthal, 1921, p. 31 y ss. 
No es, pues, de extrañar que ante tales invectivas se haya ido reduciendo el uso de la gramática hasta desaparecer por completo de las clases de idiomas, y con base en ellas se concluye, como se ha podido apreciar: no se la necesita. Realmente se puede aprender alemán $-\mathrm{y}$ no sólo cuando se es niño - sin prestar atención a la gramática. "En toda mi vida, nunca he tenido una clase de alemán, a excepción de la de Siegfried Lenz", dijo en 1983 Gabriel Laub, escritor satírico que en 1968 llegó a la Alemania Federal a la edad de $\mathbf{4 0}$ años, sin saber una sola palabra de alemán, y que desde entonces ha escrito una docena de libros en este mismo idioma. "Yo no sabia alemán; nunca lo he estudiado formalmente, ni siquiera ahora. No sé ninguna de las reglas gramáticas o ¿se dice gramaticales?"4

Incluso, lejos de las dos Alemanias, es posible encontrar personas cuya lengua materna no es el alemán y que se ufanan de no saber distinguir entre el infinitivo y el genitivo utilizando un alemán muy pulido. Aprendieron el idioma fuera del salón de clases o en él, pero sin agobiarse de conocimientos teóricos acerca del idioma. Y nadie se atrevería a echárselo en cara, como lo hiciera "el joven erudito" con sus discípulos:

Damis: ¿Así que crees que sabes alemán?

Anton: ¿Yo?, ¿yo? ¿Que no sé alemán! Sería un gran tonto si yo hablara el calmuco y no lo supiera.

Damis: Entre saber hablar y saber una lengua hay una enorme diferencia. Que tú sepas alemán significa que puedes expresar tus pensamientos con sonidos que son comprensibles para un alemán; es decir, con sonidos que despiertan en él los mismos pensamientos que tú tienes. Pero no sabes alemán en el sentido de que no eres capaz de distinguir en esta lengua lo que es normal de lo que es bajo, lo que es ofensivo de lo que es aceptable, o lo ambiguo de lo comprensible, lo anticuado de lo cotidiano. No sabes las reglas y tampoco tienes los conocimientos formales de la lengua. 5

Una de las innovaciones beneficiosas de los "métodos prácticos" de la actualidad es, sin lugar a dudas, que ya no se exige a los examinados conocimientos formales de la lengua, como ocurría en la época de Oloardo Hassey. En aquel momento debían saber responder preguntas como: ¿Cómo se puede saber el género de los sustantivos? y ¿qué debe hacer el estudiante para descubrirlo? ¿existen contracciones en alemán? ¿cuántas declinaciones hay y en qué se diferencian? ¿cuántas clases de partículas existen? etcétera. ${ }^{6}$

Pero, ¿por qué -y este por qué debiera escribirse con mayúsculas - sigue habiendo cursos de alemán que en realidad son, e incluso se llaman, cursos de

4 Laub, 1983, p. 1872.

5 Lessing, sin fecha, p. 47.

6 Hassey, 1872, p. 88 y ss.

"Se refiere a la novela de Siegfried Lenz intitulada "La clase de alemán" (Die Deutschstunde). 
gramática? Y ¿a qué se debe que estos cursos estén llenos de alumnos interesados? ¿Por qué - contra lo que cabría esperar - muchos de los alumnos prefieren repetir un curso, a pesar de haber aprobado el examen final, o incluso están dispuestos a volver a empezar desde el principio con el fin de entender la gramática? ¿Por qué un resplandor invade el rostro de muchos estudiantes de alemán al relatar que por fin tienen un(a) maestro(a) paciente que ha logrado aclararles éste o aquel problema de gramática? ¿Será que los maestros de gramática no son tan antipáticos como los pinta la tradición? $\mathrm{O}$ ¿será que detrás de su aparente pedantería la gramática esconde algo más que simple aburrimiento estéril? ¿De qué manera se puede explicar el hecho de que todo un grupo de alumnos de alemán que participa con interés y obstinación en la realización de áridos ejercicios de sustitución, protesta y se rebela cuando al final de una práctica se les pide que elaboren un diálogo? El diálogo más entusiastamente aplaudido reza así:
A: Wir müssen einen Dialog machen.
B: Ich habe keine Zeit.
C: Ich habe keine Lust.
B: Mein Kopf tut weh.
D: Ich hasse Dialoge machen.
A: Und ich habe Hunger. Ich will jetzt etwas essen.

(Tenemos que hacer un diálogo)

(No tengo tiempo)

(No tengo ganas)

(Me duele la cabeza)

(Odio hacer diálogos)

(Y yo tengo hambre)

(Y quiero comer algo ahora)

Tal vez habria que agregar que se trata de un equipo muy bueno y de una clase sobresaliente. Después de los aplausos de sus compañeros, los actores agregaron en español que estarían dispuestos a realizar cualquier otra actividad, pero que ya estaban hartos de diálogos y de jugar a desempeñar papeles. Pero, " ¿Y ejercicios de gramática? Sí, claro, son divertidos, además son útiles, con eso se puede aprender algo". El desconcierto se apodera del observador, quien considera, de acuerdo con Herder y la tradición alemana, que para el alumno la gramática no es otra cosa que "un edificio muerto que le causa tormento". Herder pensaba en los estudiantes de segundo grado de enseñanza secundaria. Sin embargo, puesto que sabemos que hay diferentes tipos de estudiantes, estamos conscientes de que lo dicho por Herder también es válido para algunos de los estudiantes adultos. Los demás sienten la necesidad de estudiar reglas gramaticales y no les parece suficiente que éstas aparezcan implícitas en el acto de la comunicación. Por consiguiente, es válido admitir la paradoja de que la gramática no es necesaria; sin embargo, puede llegar a ser útil.

\section{2. ¿Para qué sirve la gramática?}

Ahora bien, si la enseñanza de la lengua y el material didáctico han de tomar en cuenta el hecho de que los receptores, por lo menos parcialmente, opinan que la 
gramática puede ser útil, surge la pregunta de para qué se la va a utilizar, puesto que ningún curso de idiomas cuyos objetivos sean la comprensión y la expresión oral y/o escrita en una segunda lengua, considera la gramática como un fin en sí mismo.

Con base en mi experiencia considero que la enseñanza de la gramática debe satisfacer dos tipos de necesidades, mismas que quisiera ilustrar mediante las siguientes imágenes: se requiere una gramática para excursionistas y otra para cocineros inexpertos.

Una vez en las montañas del idioma extranjero a más de uno lo invade la inseguridad y siente la necesidad de una orientación. Un guía y/o un buen mapa pueden ayudar a recuperar la confianza. Lo curioso es que para quien se encuentra perdido no es tan importante que la ubicación de la posición en el mapa sea cien por ciento exacta. En varias ocasiones he sido testigo de que indicaciones mediana o totalmente equivocadas producen el mismo efecto sedante que las indicaciones linguiisticamente fundamentadas. El excursionista puede vivir en la inseguridad, si está convencido de que las cosas tiene algún orden y de que el guía todo lo tiene bajo control. Dicho en otras palabras, a menudo se piden aclaraciones gramaticales no tanto para llegar a entender cómo funciona la lengua extranjera, sino más bien para superar la sensación de extravio, y para recuperar así la confianza en sí mismo. Hasta ahora, nunca me he encontrado un grupo que no pida explicaciones de las formas de los diferentes casos de los artículos. Si se les responde que son cosas del idioma y que no deben preocuparse por la teoría, dejarán de preguntar, pero no porque sientan que sus dudas hayan quedado resueltas, sino porque sienten que se trata de una especie de tabú; tal y como sucede cuando los pequeños dejan de preguntar de dónde vienen los niños, si se les despacha con la respuesta de que son todavía muy pequeños para esas cosas.

La gramática para los cocineros inexpertos consistirá en recetas redactadas de manera tan atractiva que todos sientan deseos de experimentarlas por sí mismos. Se puede afirmar que la mayoría de los estudiantes de lenguas extranjeras sienten la necesidad cuasi estética de manejar la segunda lengua no sólo de una manera comprensible, sino lo más pulcramente posible. Aun cuando ya no se sancionan los errores, los estudiantes anhelan producir un alemán impecable. Todo aquello que les ayude a alcanzar este objetivo es muy bien aceptado, siempre y cuando no sea más complicado que los enunciados que se construirán.

En ciertos casos se logra que incluso aquellos a quienes no les interesa la cocina se pongan a experimentar alguna de las recetas. Si bien la exclamación "¡sí funciona!" no indica una conversión al método explícito, por lo menos es muestra de que la aplicación de reglas a veces también puede producir satisfacción.

A partir de las opiniones de un buen número de estudiantes he llegado a la siguiente conclusión: la gramática es bienvenida siempre y cuando no se presente en una manera muy compleja, ni confusa, ni aburrida. Se la percibe como una ayuda, si logra disipar dudas o si ofrece recetas prácticas y de fácil aplicación. En los casos en los que la educación primaria y media no haya creado en los alumnos una actitud de rechazo en contra de todo lo que se llama o huele a gramática, se puede sacar 
mucho provecho de la alianza entre ésta y el anhelo de perfeccionismo. El quid está en que las explicaciones y las actividades de apoyo empiecen justamente en los umbrales de la comprensión del grupo respectivo y no más allá.

El intercambio de opiniones con estudiantes mexicanos, a lo largo de muchos años, ha resquebrajado el prejuicio que yo tenía con respecto a que la gramática es la cosa más aburrida del mundo, prejuicio que había sobrevivido incólume a mis años de colegio y de estudio de la lingüística. Pero en el momento en que ya como maestra traté de evitarles a los alumnos esa "cosa tan aburrida", me dieron ellos una mejor lección, puesto que me ogligaron a pensar más bien en cómo se podría presentar la enseñanza de la gramática de una manera práctica y atractiva.

\section{La gramática en bandeja de plata}

Puesto que el hecho de que el material empleado sea atractivo tiene una importancia decisiva en el éxito del aprendizaje, no se debe presentar la gramática como un destilado insípido o amargo, sin ninguna relación con algo tan lleno de vida como es la comunicación. Si en las clases y en los libros de texto se derrocha imaginación en la presentación de actividades encaminadas a fomentar la interacción comunicativa, y al tratar la gramática sólo se ofrecen listas escuetas y ejercicios áridos, no es de extrañar que se considere a la gramática como algo falto de atractivo; es decir, como algo que ni estimula ni produce interés en el alumno.

Los que sí funcionan como verdaderos estímulos se apoyan en situaciones de comunicación real y por ende en la "transitividad" de la lengua; ${ }^{8}$ esto es, concentran la atención en el significado y olvidan el significante. La pregunta que surge, entonces, se puede formular en los siguientes términos: ¿existen otros recursos que permitan hacer más atractiva la gramática?

Friedrich Gottlieb Klopstock ya había reflexionado sobre esto. En sus Conversaciones de Gramática ${ }^{9}$ permite que la imaginación amoneste a la gramática, "Pues no admito esta inefable aridez". Por su parte, la sensibilidad hace el siguiente comentario:

De ninguna manera puede ser contraproducente que quien quiere enseñar algo haga más agradable su materia, y en realidad indicaría falta de perspicacia si sólo tratara de circunscribirse a la corrección de las definiciones teóricas. Es cierto que puede enseñar algo, pero seguramente nadie querrá aprender nada de alguien así.

Gramática + imaginación + sensibilidad. ¿Será esta noción, tan antigua y tan novedosa, una receta adecuada para la presentación de la gramática en la enseñanza del alemán? Pero, ¿cómo se podría poner en práctica?

Harald Weinrich ${ }^{10}$ propuso, como medio para lograrlo, recurrir a la función estética de la lengua. Es cierto, en el jardín de la poesía moderna y del cuento corto

8 Vid. Weinrich, 1979, p. 3.

9 Citado por Elschenbroich, 1973, p. 191 y ss.

10 Weinrich, 1979 y 1983. 
se pueden encontrar muchas plantitas que podrían adornar un capítulo de gramática. Sobre todo la poesía moderna, ya que es, hasta cierto punto, tan artesa nal que no sufre daño alguno si se juega un poco con ella o si se la utiliza para hacer ejercicios. A partir del texto original los alumnos pueden, de inmediato, poner en juego su imaginación. Las ideas del poeta avivan la fantasía de los estudiăntes y la rigidez del esquema formal obliga a prestar atención al significante. Ahora bien, yo quisiera llamar la atención sobre las desventajas que puede traer consigo el hecho de explotar con demasiada frecuencia la carga gramatical de los textos poéticos. El peligro de que se pierda o se estropee el goce estético es demasiado grande. Recordemos algunos versos del poema "El Carrusel" de Rainer Maria Rilke: De vez en vez un elefante blanco causa placer y anticipa el placer de la próxima vez. Pero no debe degenerar en "un elefante otra vez".

Por ello mi propuesta queda un paso atrás de la de Weinrich. Yo sugiero que se aproveche la función lúdica del idioma, ya que ta mbién ésta concentra el interés en el significante. Jugar con el idioma implica conocer bien sus reglas y aplicarlas adecuadamente con el fin de producir determinados efectos. ¡Es asombrosa la cantidad de tiempo que los niños dedican a jugar con el idioma cuando están aprendiendo a hablar! Y también es asombroso todo lo que logran los adultos jugando con las palabras. Entonces, ¿por qué no aprovechar estos intereses genuinos para enseñar la gramática?

Cabe aclarar que en este estudio no me estoy refiriendo ni a los juegos del lenguaje en el sentido de Wittgenstein, ni a los juegos pedagógicos que se practican tanto en la lengua materna como en la extranjera, y que despiertan una ambición en algunos estudiantes y disgusto en los perdedores o en aquellos que los toman demasiado en serio. Más bien me refiero a la función lúdica propiamente dicha, a las posibilidades de innovar el lenguaje que además de proporcionar diversión permiten fijar la atención en un problema específico; lo que estoy sugiriendo es que los paradigmas gramaticales se presenten como si fueran juguetes. Quizá no tengan el valor artístico de las creaciones poéticas, pero por lo menos resultarán más atractivos que las áridas tablas de gramática y que los ejercicios fuera de contexto. De esta manera se suspende la "transitividad" de la lengua, sin que automáticamente se caiga en el aburrimiento.

Los juegos de palabras, presentes tanto en las rondas infantiles como en los dichos populares, pueden dar pie a reflexiones acerca de la gramática. Sirva de ejemplo lo siguiente:

Die Menschen sind schlecht.

Sie denken an sich.

Nur ich denk an mich.
(Los hombres son malos)

(Todos piensan en sí mismos)

(Sólo yo pienso en mí)

Se canta como canon y tiene la ventaja de que es tan fácil que incluso grupos sin conocimientos musicales lo pueden cantar. 


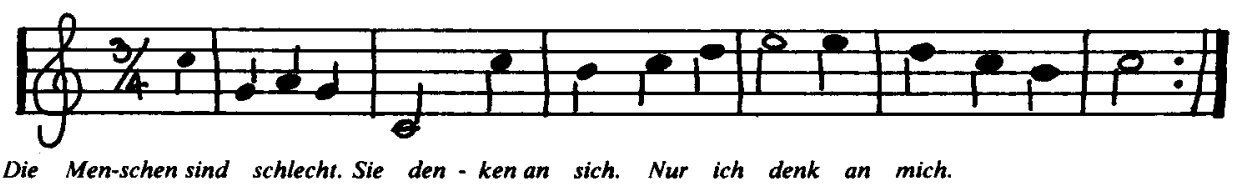

El problema de las formas de acusativo y de dativo se encuentra plasmado en la siguiente rima popular de origen berlinés:

Ik liebe dir, ik liebe dich

Was richtig ist, das weiss ich nich'

Ob dritter oder vierter Fall

Ik liebe dir auf jeden Fall
(Ti amo, te amo

qué es correcto, no lo sé

Si la tercera o la cuarta forma

Yo ti amo a tí de cualquier forma)

Los alumnos pueden traducirlo a alto alemán o repetirlo varias veces en alemán estándar, pero empleando otros verbos, por ejemplo, kennen, glauben, sehen, helfen, etcétera (conocer, creer, ver, ayudar).

Si ni en el repertorio poético, ni en el infantil, ni en el popular se encuentra algo que pudiera aplicarse a un tema, cabe recordar que algunos puntos de gramática se prestan para jugar. ¿Se podría explicar la valencia de los verbos con una pequeña "educación sentimental gramatical"?:

Vorwürfe

Ich habe dir genützt

Du hast mich ausgenützt

Ich habe dir geraten

Du hast mich verraten

Ich hab' mich auf dich verlassen

Doch du hast mich verlassen.

\section{Reproches}

(Te serví,)

(Te aprovechaste de mí,)

(Te aconsejé,)

(Y me traicionaste,)

(Confié en ti,)

(Y me abandonaste.)

A partir de mi experiencia, puedo asegurar que a los participantes del curso no les molesta repetir estos textitos cambiando los pronombres utilizados, por ejemplo:

Sie hat ihm genützt

Er hat...

Er hat ihr genützt

Sie...
(Ella le sirvió,)

(Él...,)

(Él le sirvió [a ella],)

(Ella...,)

puesto que pueden utilizar el modelo, bastante sencillo, como guía y, además, darse cuenta de que están aprendiendo algo, sobre todo sin sufrir en exceso.

Servir la "gramática en bandeja de plata" significa, para mí, extraer de la parte-significativa de la lección los puntos gramaticales introducidos por primera vez y presentarlos, por así decirlo, como apetitoso platillo extra. Como aderezos se pueden emplear tanto recursos lingüísticos como gráficos. Cuanto más árido sea el tema, tanto más atractiva debe ser la presentación. El mundo rebosa de medios seductores de los cuales bien podríamos servirnos. 


\section{Gramática pedagógica}

Si la enseñanza del alemán ha de responder a las necesidades de los diferentes tipos de aprendizaje, tendrá que hacerse más flexible la enseñanza de la gramática. Es necesario que los estudiantes con diferentes tipos de aprendizaje tengan la posibilidad de expresar sus experiencias, sus impresiones y sus dudas de modo tal que las reflexiones sobre la lengua extranjera y su adquisición les permitan, a cada uno de los participantes en un curso, reconocer sus características psicológicas y desarrollar las estrategias adecuadas para mejorar su aprendizaje. La adquisición de una lengua extranjera, en los adultos, va acompañada de una gran cantidad de emociones, como por ejemplo, la alegría del explorador, el gusto por el disfraz y la metamorfosis, el temor a lo extraño, el miedo a cometer errores, la contrariedad por los mismos, la impaciencia ante el elemento desconocido, las experiencias de éxito o de fracaso, etcétera. Todo ello genera genuinos temas de conversación dentro del salón de clases; el diálogo abierto puede reducir las tensiones e influir favorablemente en la predisposición hacia el aprendizaje. Por esto me parece, pues, muy importante que el concepto de gramática pedagógica quede integrado en el marco de la psicología del aprendizaje.

La interrogante acerca del modelo de gramática quizá no sea tan interesante para los alumnos como para el maestro. Desde mi punto de vista, todo modelo se encuentra endeudado con la gramática tradicional, que ya ha descrito la mayor parte de las regularidades que se pueden enseñar.

Esto no quiere decir, sin embargo, que haya que cerrarse al progreso lingüístico; mientras las diferentes escuelas lingüísticas se sigan diferenciando entre sí por el estudio de fenómenos linguísticos distintos, la gramática pedagógica tendrá que seguir trabajando de manera ecléctica. Así, por ejemplo, para presentar adecuadamente la valencia de los verbos se recurre a la gramática de la dependencia; ${ }^{11}$ para poder explicar el orden de las palabras en la oración se requieren además elementos de la linguística del texto, que han sido tratados por la teoría de la Perspectiva Funcional de la Oración. La lingüística del texto también ayuda a explicar el funcionamiento de los conectores; es decir, los elementos que retoman la información de oraciones precedentes y la conectan con la nueva información. Las partículas modales, ${ }^{12}$ en cambio, se explican mejor a partir de su función pragmática; esto es, como señales que indican la manera como los interlocutores negocian sus relaciones personales.

En un modelo de este tipo hay que considerar dos cosas: primero, el modelo debe ser coherente consigo mismo, las teorias subyacentes no deben llevar contradicciones en la presentación de los datos. En segundo lugar -y esto es todavia más importante para el receptor - el modelo debe ser didácticamente adecuado a la población a la que va dirigido. Las innovaciones lingüísticas más fascinantes no sirven de nada si en el salón de clase sólo provocan miradas de interrogación. 
Adecuado a la población a la que está dirigido significa, por un lado, que las preguntas a las cuales la Gramática Pedagógica pretende dar respuesta no estén tomadas del campo de la lingüística, sino de los mismos salones de clase. Por otro lado, los fenómenos incluidos deben ser denominados y presentados de tal manera que también el profesor sin formación lingüística se sienta animado a tratarlos así. En otras palabras, la Gramática Pedagógica no es algo que un lingüista teórico pueda elaborar en la soledad de su estudio. Más bien es el resultado de un largo regateo entre autor y coautor, entre el lingüista y el pedagogo, entre el maestro y los alumnos.

Una Gramática Pedagógica de este tipo debe ofrecer al excursionista una parte de comentarios que le permita hacer preguntas cuando algo le llame la atención o cuando se sienta inseguro. A los cocineros inexpertos, en cambio, debe proporcionarles explicaciones, cuadros y reglas gramaticales que puedan ser aplicadas inmediatamente; puesto que a ellos les interesa la aplicación inmediata y no la teoría improductiva.

Siguiendo los sentimientos de Goethe, la Gramática Pedagógica procura presentar la parte más a mena y accesible de la gramática. De acuerdo con las ideas de Klopstock, la gramática se asocia a la imaginación y a la sensibilidad para crear ejercicios amenos. $Y$ teniendo en cuenta lọs consejos de Hofmannsthal y de los profesores de lengua que deseen enseñarla de una manera viva, se presenta a la gramática como un apetitoso platillo y se la vuelve a subordinar a los objetivos de la enseñanza del alemán. Para dar un ejemplo práctico, tomaremos un libro de texto que apenas está en proceso de formación. ${ }^{13}$ En la lección 6 se introducen, entre otras cosas, la declinación de los adjetivos y los adjetivos que designan los colores. Se ejercitan a mbos paradigmas a partir de la descripción de un escenario visto a través de lentes de diversos colores. Los primeros lentes son de color lila. En el momento en que éstos son cambiados por otros de color rojo, todos los objetos se vuelven rojos. Esto implica el agregar las terminaciones a los adjetivos, ya que el color lila es un adjetivo que no se declina en alemán, pero el rojo sí. Es decir, se trata de un simple ejercicio de declinación, pero temáticamente bien cimentado, con un contenido bien configurado con chispa suficiente como para combatir la "inefable aridez". El siguiente paso nos coloca ya en el nivel de la "lengua viva", de la convivencia con los demás, del jugar, del aconsejar y del interca mbiar opiniones. $Y$ puesto que la gramática, el vocabulario y los temas están inscritos en el marco conceptual del diálogo intercultural, las partes mencionadas nos llevan de nuevo a la percepción de lo extraño, de la otredad, esto es, a la contemplación de la cultura alemana desde afuera. Los colores no sólo se declinan, sino que también se brinda con ellos información acerca de su contenido simbólico en las respectivas culturas, al relacionarlos con la forma de vestir, las apreciaciones, los estereotipos y los prejuicios que forman y deforman nuestra percepción del otro.

13 Se trata del libro de texto para la enseñanza del alemán como lengua extranjera que lleva el título de Sprachbrücke, que aparecerá a mediados de 1986 en la editorial Ernst Klett en Stuttgart. 
Puesto que cuando alguien empieza a aprender una lengua tan difícil como el alemán, raras veces emprende tal aventura por razones puramente utilitarias, el idioma debe funcionar como un puente de acceso a la otra cultura. Por ello, la Gramática Pedagógica intenta integrarse, de forma modesta pero grata, al concepto del diálogo intercultural.

\section{APENDICE}

23. Qué casos rigen los verbos alemanes?

Hay verbos que rigen

el nominativo como:

sein, werden, bleiben, heissen, por ej.

ich bin ein Schuhmacher, soy zapatero

el Genitivo, como: einer Sache bedürfen, necesitar una cosa

eines Dinges erwahnen, mencionar una cosa

sich einer Sache bemächtigen, apoderarse de una cosa

el Dativo, como: einem etwas sagen, decir algo a alguno

einem etwas versprechen, prometer algo a alguno

el Acusativo, como: jemanden fragen, preguntar a alguno

einen schlagen, pegar a alguno.

La lectura atenta enseñará mejor que reglas el empleo y régimen de los verbos, y el cambio de significado por las preposiciones con que se componen.

\section{BIBLIOGRAFIA}

ELSCHENBROICH, E. "Bildungswert des Grammatikunterrichts". Zur Didaktik der deutschen Grammatik. Ed. H.G. Rötzer, Darmstadt, 1973, pp. 171-208.

HASSEY, O. Método práctico para aprender el idioma alemán. México, 1872.

HOFMANNSTHAL, H.v. Reden und Aufsätze. Leipzig, 1921.

LAUB, G. "Autoren-Interview". Börsenblatt 72, 9.9.1983, p. 1872.

LESSING, G.E. Der junge Gelehrte. Lessings Werke, Dritter Teil. Berlin, Leipzig, Wien, Stuttgart, Bong, s.f., pp. 43-120.

RALL, M./ ENGEL, U./ RALL, D. Dependenz-Verb-Grammatik für Deutsch als Fremdsprache. Heidelberg, Groos, 1977.

WEINRICH, H. "Von der Langeweile des Sprachunterrichts". Informationsdienst "Spracharbeit", 2/79. München, 1979. pp. 1-21.

_-_. "Literatur im Fremdsprachenunterricht - ja, aber mit Phantasie". Die Neueren Sprachen. Frankfurt/ M. 1983.

WEYDT, H./ HARDEN, Th./ HENTSCHEL, E./ RÖSLER, D. Kleine deutsche Partikellehre. Stuttgart, Klett, 1983.

Traducción de Rocío Madrid, Laura Chávez y Gerardo del Rosal. 